\title{
'n Vergelyking van die persepsies van die relatiewe belang van evalueringskriteria tussen verbruikers en verkoopskonsultante by die aankoop van 'n passasiersmotorvoertuig
}

\author{
P.J. du Plessis ${ }^{*}$ \\ Skool vir Bedryfsleiding, Universiteit van Suid-Afrika, Posbus 392, Pretoria, 0001 Republiek van Suid-Afrika \\ C. Boshoff \\ Departement Bedryfsekonomie, Universiteit Vista, Privaatsak X613, Port Elizabeth, 6000 Republiek van Suid-Afrika
}

\begin{abstract}
The acceptance of the marketing concept and the implementation of the principles on which it is based presupposes a thorough knowledge of market needs. If the marketing concept is applied at retail level in the South African motor industry, one should be able to assume that there is a high degree of agreement regarding the perceptions of consumers and sales personnel of what is important to a purchaser when buying a motor vehicle. The validity of this statement was tested by means of the following null-hypothesis: There is no difference with regard to the relative importance attached to different evaluation criteria between consumers and sales personnel, with the purchase of a passenger vehicle. Information provided by 902 consumers and 207 sales personnel revealed that significant differences $(p<0,01)$ exist between the two groups with regard to 35 evaluation criteria and a further four criteria on the 0,05 level. The null-hypothesis is thus rejected with regard to 39 evaluation criteria in favour of the alternate hypothesis.
\end{abstract}

\begin{abstract}
Die aanvaarding van die bemarkingskonsep en die toepassing van die beginsels waarop dit gebaseer is, veronderstel ' $n$ grondige kennis van die behoeftes van die mark wat bedien word. Indien die bemarkingskonsep op kleinhandelvlak in die Suid-Afrikaanse motorbedryf toegepas word, behoort aanvaar te kan word dat motorkopers en verkoopkonsultante grootliks behoort ooreen te stem wat die relatiewe belangrikheid van verskillende evalueringskriteria by die aankoop van 'n passasiersmotorvoertuig betref. Die geldigheid van die stelling is getoets aan die hand van die volgende nul-hipotese: Daar is geen verskil wat betref die relatiewe belangrikheid wat verkoopskonsultante en verbruikers aan evalueringskriteria heg by dic aankoop van 'n passasiersvoertuig nie. Inligting verskaf deur 902 verbruikers en 207 verkoopskonsultante het getoon dat beduidende verskille $(p<0,01)$ tussen die twee groepe bestaan wat 35 evalueringskriteria betref asook ten opsigte van 'n verdere vier kriteria op die 0,05 -vlak. Die nulhipotese word daarom ten opsigte van 39 evalueringskriteria verwerp ten gunste van die alternatiewe hipotese.
\end{abstract}

* Aan wie korrespondensie gerig behoort te word

Een van die mees invloedryke ontwikkelings op die gebied van bemarking was die toenemende mate waarop ondernemings sedert die laat vyftigerjare die belange van verbruikers in handelstransaksies voorop gestel het. Die benadering tot bemarking word getipeer deur die sogenaamde bemarkingskonsep en word deur Kotler \& Armstrong (1987: 15) as volg gedefinieer: 'The marketing concept holds that achieving organizational goals depends on determining the needs and wants of target markets and delivering the desired satisfactions more effectively and efficiently than competitors.

Die onderliggende beginsels waarop die bemarkingskonsep gebaseer is, is die volgende (Kotler 1980:31):

- Op grond van verbruikersbehoeftes kan 'n verbruikersmark in verskillende segmente verdeel word. - Die verbruikers in enige marksegment sal die onderneming ondersteun wat die beste daarin slaag om hul besondere behoeftes te bevredig.

- Dit is die onderneming se taak om, gebaseer op voldoende navorsingsinligting, 'n marksegment te selekteer, 'n markaanbod saam te stel en 'n bemarkingsprogram te formuleer wat optimaal daarin sal slaag om verbruikersbehoeftes te bevredig.

'n Sleutelaspek van die bemarkingskonsep is voldoende inligting oor verbruikersbehoeftes aangesien bemarkingsbesluite daarop gebaseer behoort te word.
Die bemarkingskonsep veronderstel dus dat nie net bemarkingsbestuur nie, maar almal betrokke by bemarkingsaktiwiteite, kennis moet dra van die behoeftes van verbruikers.

Indien hierdie uitgangspunt op kleinhandelvlak in die Suid-Afrikaanse motorbedryf toegepas word, behoort aanvaar te kan word dat motorkopers en verkoopskonsultante grootliks behoort ooreen te stem wat die relatiewe belangrikheid van verskillende evalueringskriteria by die aankoop van 'n passasiersmotorvoertuig betref. Die geldigheid van die stelling is empiries getoets aan die hand van die volgende hipotese.

$\mathrm{H}_{0}$ : Daar is geen verskil wat betref die relatiewe belangrikheid wat verkoopskonsultante en verbruikers aan evalueringskriteria heg by die aankoop van 'n passasiersmotor nie.

Die rasionaal vir die nulhipotese is dat die belangrikste oorsprong van evalueringskriteria vir die verbruiker in waardes, motiewe, inligting en ervaring lê. (Cohen, 1981: 373). 'n Verbruiker versamel die kriteria en evalueer die produk dan in terme van die belangrikheid daarvan vir homself in 'n bepaalde koopsituasie. Vir die bemarker, en meer in besonder vir die verkoopskonsultant, is dit noodsaaklik om 'n begrip van die evalueringskriteria van die verbruiker te hê ten einde die verkoopsonderhandeling met sukses te beklink. 


\section{Literatuuroorsig}

In 'n Amerikaanse studie, wat afgehandel is tydens die Volkswagen-Dasher (die Passat in Suid-Afrika) se bekendstelling in 1974, het kopers sekere evalueringskriteria ten minste een keer genoem as redes waarom die motor gekoop is. Die kriteria word in Tabel 1 getoon.

Die handelaarspersoneel wat die Dasher verkoop, het egter ander kriteria vooropgestel. 'n Weergawe van die kriteria wat deur verkoopskonsultante benadruk is, verskyn in Tabel 2.

Ideaal gesproke, behoort daar 'n baie nou ooreenstemming tussen die evalueringskriteria van die verbruiker en die verkoopsaanbieding te wees. Indien Tabel 1 en Tabel 2 met mekaar vergelyk word, kan gesien word dat die relatiewe belangrikheid van

Tabel 1 Evalueringskriteria genoem as rede vir aankoop van die Volkswagen Dashermotor (Bron: Engel, et al., 1978: 36)

\begin{tabular}{lc}
\hline Evalueringskriteria & Persentasie genoem* \\
\hline Ekonomiese brandstofdoeltreffendheid & 79,7 \\
Reputasie van vervaardiger & 28,9 \\
Gehalte van vakmanskap & 22,8 \\
Vorige ervaring met fabrikaat & 21,3 \\
Waarborgdekking & 18,2 \\
Herverkoopwaarde & 18,2 \\
Gemaklike hantering & 13,4 \\
Binneruimte & 13,0 \\
Waarde vir geld & 6,6 \\
Stilering & 6,5
\end{tabular}

- Persentasies is meer as $100 \%$ as gevolg van multiresponsies per kriteria

Tabel 2 Kriteria wat op die tydstip van aankoop deur verkoopskonsultant genoem is (Bron: Engel, et al., 1978:36)

\begin{tabular}{lc}
\hline Evalueringskriteria & Persentasie genoem \\
\hline Ekonomiese brandstofdoeltreffendheid & 28,8 \\
Ruimheid & 17,0 \\
Voorwielaandrywing & 16,2 \\
Hantering/bestuursgerief & 14,4 \\
Lae bedryfskoste & 12,9 \\
Instandhoudingswaarborg & 8,5 \\
Enjin (waterverkoel/voorwielaandrywing) & 8,1 \\
Werkverrigting & 5,9 \\
Ontwerp/stilering & 5,5 \\
Standaardeienskappe & 5,5 \\
Diens & 5,5 \\
Kwaliteit van vakmanskap & 4,4 \\
Veiligheid & 4,4 \\
Ingenieursgevorderdheid & 4,4 \\
Ander & 45,1 \\
Geen (swak verkoopkuns) & 14,8 \\
\hline
\end{tabular}

-Persentasie is meer as $100 \%$ as gevolg van multi responsies per kriteria ekonomiese brandstofdoeltreffendheid, in die geval van die koper en die verkoopskonsultant ooreenstem.

Die reputasie van die vervaardiger, wat die tweede meeste deur kopers gemeld word, is glad nie deur die verkoopskonsultante genoem nie, en gehalte van vakmanskap (derde belangrikste vir die koper) verskyn heelwat laer af in die hiërargie van die verkoopskonsultant. Aspekte wat deur verkoopskonsultante beklemtoon word, is hantering, ruimheid, voorwielaandrywing en lae bedryfskoste.

Min is deur die handelaar gedoen om op die reputasie van die vervaardiger en vorige ervaring met Volkswagen, te kapitaliseer. Oor die keuse van die betrokke handelaar het $41 \%$ van die respondente aangedui dat dit op grond van die handelaar se nabygeleë ligging gekies was, terwyl $11 \%$ gesê het dat dit as gevolg van vorige ervaring was. Ander redes soos diens, personeel van handelaar, reputasie van handelaar, en inruilwaarde se responsies het tussen $6 \%$ en $8 \%$ gewissel.

Vorige navorsing deur Stewart \& Hood (1981:10-19) met twee produkgroepe motors in Europa, het bevind dat die twee belangrikste attribute vir albei groepe, prys en betroubaarheid was. Volgens Rousseau (1977: 175-183) is die belangrikste eienskappe in motorkeuse by Suid-Afrikaanse kopers padhouvermoë, werkverrigting, rygerief en verkoopprys.

In 1981 het SAAN gesindikeerde navorsing in SuidAfrika oor kopers van nuwe motors laat uitvoer (Newsdesk, 1982). Die steekproef het uit 950 blanke respondente bestaan - hoofsaaklik mans. Respondente is onder andere gevra om 30 eienskappe, volgens die belangrikheid daarvan, te evalueer by die keuse van 'n motor. Die studie het bevind dat die vyf mees belangrike attribute betroubaarheid, padhouvermoë, werkverrigting, brandstofdoeltreffendheid en gehalte van vakmanskap is.

In 1982 en 1984 is vergelykbare studies deur SAAN geloods (Newsdesk, 1983). Tussen 1981 en 1982 het veral brandstofdoeltreffendheid, gehalte van afwerking en veiligheidsaspekte in belangrikheid toegeneem, terwyl 'n vergelyking tussen 1982 en 1984 toon dat binneruimtegemak effens belangriker in die ondersoek van 1984 geword het. Brandstofdoeltreffendheid skyn asof dit nie meer so belangrik in 1984 as in 1982 en 1981 was nie.

In die lig hiervan is die geformuleerde hipotese getoets en is gepoog om die evalueringskriteria te identifiseer waarby die grootste verskille tussen verbruikers en verkoopskonsultante voorkom.

\section{Metodologie}

Die navorsingsmetode wat gebruik is, het die trek van twee steekproewe genoodsaak, naamlik 'n handelaarsteekproef en 'n verbruikersteekproef, aangesien respondente (die kopers van passasiersvoertuie) vraelyste by die punt van verkope, dit wil sê op die motorhandelaar se perseel, voltooi het (Du Plessis, 1986: 165). 


\section{Handelaarsteekproef}

'n Ontleding van die registrasie van nuwe en gebruikte motorvoertuie (alle rassegroepe) toon 'n groot mate van konsentrasie in metropolitaanse gebiede. Vir die doeleindes van die studie is die universum gedefinieer as alle blankes, kleurlinge, Asiërs en swartes wat 'n passasiersmotorvoertuig gedurende die tydperk Desember 1985 tot Mei 1986 gekoop het by handelaars in die PWV-, Durban-, Kaapstad- en Tzaneen-Pietersburggebied.

In totaal is 871 motorhandelaars (nuwe en gebruikte motors) geïdentifiseer, waarvan 125 aangedui het dat hulle bereid is om aan die studie deel te neem. Die geografiese verspreiding van die handelaarsteekproef en verkoopskonsulktante-responsies word in Tabel 3 aangetoon.

Tabel 3 Steekproef van handelaars in geselekteerde gebiede en aantal vraelyste deur verkoopskonsultante voltooi

\begin{tabular}{lcc}
\hline & \multicolumn{2}{c}{ Aantal } \\
\cline { 2 - 3 } Streek & Handelaars & $\begin{array}{c}\text { Vraelyste deur verkoops- } \\
\text { konsultante voltooi }\end{array}$ \\
\hline PWV & 62 & 169 \\
Durban-Pinewtown & 19 & 21 \\
Kaap & 23 & 13 \\
Tzaneen-Pietersburg & 21 & 4 \\
Totaal & 125 & 207 \\
\hline
\end{tabular}

Motorhandelaars wat in die handelaarsteekproef opgeneem is het 'n tweeledige funksie vervul, naamlik die verskaffing van vraelyste aan die kopers van motorvoertuie en ook die invul van afsonderlike vraelyste deur verkoopskonsultante van die handelaar.

\section{Verkoopskonsultantevraelys}

Soos in Tabel 3 aangetoon het 125 handelaars aan die studie deelgeneem. In die verkoopskonsultante-vraelys is 65 evalueringskriteria aan verkoopskonsultante voorgelê met die versoek om, met enige motor waarmee hulle bekend is as verwysingspunt, die kriteria aan te slaan soos wat hulle dink die verbruiker dit sou evalueer. Respondente is ook gevra om die sewe mees belangrike evalueringskriteria in 'n dalende volgorde van belangrikheid te rangskik. 'n Totaal van 207 vraelyste is van verkoopskonsultante ontvang en die verspreiding volgens geografiese gebied word in Tabel 3 aangetoon. Dit word aanvaar dat die verkoopskonsultante se responsies nie deur geografiese ligging beïnvloed word nie.

\section{Verbruikersvraelys}

Weens die inligtingsinwinningswyse wat gebruik is, kon die grootte van die steekproef en die steekproefraamwerk van die verbruikers (kopers) nie vooraf bepaal word nie, want dit was nie vooraf bekend wie in die geselekteerde gebiede passasiervoertuie sou aankoop nie.

Verbruikersrespondente is deur middel van 'n gestruktureerde vraelys versoek om die relatiewe belang van 65 evalueringskriteria in hul besluit om 'n bepaalde motorvoertuig te koop op 'n sespunt skaal te evalueer. Verder is respondente versoek om die sewe mees belangrike evalueringskriteria van die belangrikste tot die minste belangrik te rangskik.

'n Totaal van 986 vraelyste is van verbruikers ontvang waarvan 902 bruikbaar was. Indien die steekproef (voltooide vraelyste) met die universum vergelyk word ten opsigte van die samestelling van nuwe en gebruikte voertuie, verteenwoordiging van verskillende motorvervaardigers (in terme van markaandeel) en geslags- en rassesamestelling, blyk dit dat 'n redelike verteenwoordigende steekproef verkry is.

\section{Resultate}

Die geformuleerde nulhipotese is met behulp van eenrigting variansie-ontleding getoets ( $F$-toets). Die gemiddeldes, standaardafwykings en $F$-waardes van die tien kriteria waar die grootste evalueringsverskille voorgekom het, word in Tabel 4 aangetoon.

Tabel 4 toon dat beduidende verskille tussen verbruikers en verkoopskonsultante by 35 evalueringskriteria op die 0,01-vlak voorkom en by vier kriteria op die 0,05 vlak. By slegs 26 kriteria kom onbeduidende verskille voor. Die nulhipotese word daarom ten opsigte van 39 evalueringskriteria verwerp ten gunste van die alternatiewe hipotese.

In Tabel 4 kan gesien word dat die grootste verskille

Tabel 4 Gemiddeldes, standaardafwykings en $F$ waardes van evalueringskriteria wat verskillend deur verbruikers en verkoopskonsultante geëvalueer is ${ }^{a}$

\begin{tabular}{|c|c|c|c|c|c|}
\hline \multirow[b]{2}{*}{ Beskrywing van kriterium } & \multicolumn{2}{|c|}{$\begin{array}{c}\text { Verbruikers } \\
n=902\end{array}$} & \multicolumn{2}{|c|}{$\begin{array}{c}\text { Verkoops- } \\
\text { konsultante } \\
n=207\end{array}$} & \multirow[b]{2}{*}{$F_{\text {-waarde }}$} \\
\hline & $\boldsymbol{X}$ & $s$ & $\boldsymbol{X}$ & $s$ & \\
\hline Invloed van verkooppersoneel & 2,915 & 1,365 & 4,309 & 1,330 & 291,91 \\
\hline Houding van verkooppersoneel & 4,118 & 1,403 & 5,188 & 0,939 & 179,72 \\
\hline Voorkoms van vertoonlokaal & 3,361 & 1,409 & 4,415 & 1,231 & 162,29 \\
\hline Mening van vriende & 3,823 & 1,281 & 3,681 & 1,353 & 121,76 \\
\hline \multicolumn{6}{|l|}{ Verhouding met verkooppersoneel } \\
\hline van handelaar & 3,971 & 1,474 & 4,884 & 1,156 & 114,58 \\
\hline T.V.-advertensie & 2,715 & 1,288 & 3,502 & 1,273 & 103,96 \\
\hline Reputasie van handelaar & 4,146 & 1,212 & 4,860 & 0,968 & 103,17 \\
\hline Goeie inruilwaarde vir vorige motor & 3,626 & 1,938 & 4,729 & 1,263 & 100,57 \\
\hline $\begin{array}{l}\text { Reputasie van na-vcrkope diens- } \\
\text { ondersteuning }\end{array}$ & 4,656 & 1,251 & 5,319 & 0,906 & 85,43 \\
\hline Radio-advertensie & 2,681 & 1,359 & 3,362 & 1,202 & 72,52 \\
\hline
\end{tabular}

- Beduidende verskille tussen verbruikers en verkoopskonsultante ( $P$ $<0,01)$ kom by 35 van die evalueringskriteria voor. Slegs die tien kriteria met die grootste $F$-waardes word getoon 
tussen verbruikers en verkoopskonsultante ten opsigte van hulle evaluering van die relatiewe belangrikheid van kriteria voorkom by invloed van verkoopspersoneel ( $F$ waarde $=291,91)$, houding van verkoopspersoneel $(F$ waarde $=179,72)$, voorkoms van vertoonlokaal $(F$ waarde $=162,29)$, mening van vriende $(F$-waarde $=$ $121,76)$ en verhouding met verkoopspersoneel van handelaar $(F$-waarde $=114,58)$.

Engel, Blackwell \& Kollat (1978: 36) het bevind dat die evalueringskriteria wat deur kopers van motors as belangrik geag word, verskillend is van die wat konsultante tydens die verkoopsonderhandeling in die vertoonlokaal vooropstel. Alhoewel die verkoopskonsultante in die huidige studie nie in die vraelys moes aandui watter evalueringskriteria hulle tydens die verkoopsonderhandeling benadruk nie, kan so 'n gevolgtrekking uit die resultate gemaak word. Verkoopskonsultante moes enige motor waarmee hulle bekend is kies, hulle in die posisie van die koper stel en die relatiewe belangrikheid van die evalueringskriteria aandui.

Kollektief beskou, kan die evalueringskriteria wat die grootste verskille tussen die twee groepe getoon het, gesien word as sou dit hoofsaaklik 'n beïnvloedings- en handelaarsdimensie het.

Respondente van albei groepe is verder versoek om die sewe belangrikste evalueringskriteria op 'n ranglys te plaas. Die gesommeerde frekwensies, soos deur

Tabel 5 Belangrikheidsvolgorde van evalueringskriteria vir verbruikers en verkoopskonsultante

\begin{tabular}{|c|c|c|}
\hline \multirow[b]{2}{*}{ Beskrywing van kriterium } & \multicolumn{2}{|c|}{ Rangorde } \\
\hline & Verbruikers & $\begin{array}{l}\text { Verkoops- } \\
\text { konsultante }\end{array}$ \\
\hline Brandstofdoeltreffendheid & 1 & 2 \\
\hline Betroubaarheid van die model & 2 & 1 \\
\hline Padhouvermoë & 3 & 7 \\
\hline Gehalte van vakmanskap & 4 & 3 \\
\hline Instandhoudingskoste & 5 & 5 \\
\hline Lae loopkoste & 6 & 6 \\
\hline Beskikbaarheid van onderdele & 7 & 14 \\
\hline Werkverrigting van enjin & 8 & $*$ \\
\hline Veiligheidskenmerke & 9 & 13 \\
\hline Aankoopprys & 10 & 11 \\
\hline Koste van onderdele & 11 & $*$ \\
\hline Reputasie van motorvervaardiger & 12 & 10 \\
\hline Gemak van bestuur & 13 & $*$ \\
\hline Enjinkrag & 14 & $*$ \\
\hline Rygemak & 15 & $*$ \\
\hline Verhouding met verkooppersoneel & $\bullet$ & 15 \\
\hline \multicolumn{3}{|l|}{ Reputasie van na-verkope diens- } \\
\hline ondersteuning & $\bullet$ & 4 \\
\hline Toekomstige herverkoopwaarde & $*$ & 9 \\
\hline Houding van verkooppersoneel & * & 8 \\
\hline Goeie inruilwaarde vir vorige motor & - & 12 \\
\hline
\end{tabular}

* Nie onder die 15 belangrikste evalueringskriteria gerang nie respondente geselekteer, is as basis gebruik om die belangrikheidsvolgorde van die kriteria te bepaal. Die resultate vir beide verbruikers en verkoopskonsultante word in Tabel 5 aangetoon.

Uit Tabel 5 kan afgelei word dat brandstofdoeltreffendheid as die belangrikste kriterium deur verbruikers beskou word. Die persepsie van verkoopskonsultante is dat betroubaarheid van die model die belangrikste kriterium is. Padhouvermoë, beskikbaarheid van onderdele, werkverrigting van enjin en veiligheidskenmerke is vir verbruikers relatief belangriker as wat die geval is by verkoopskonsultante. Reputasie van motorvervaardiger, reputasie van na-verkope diensondersteuning, verhouding met verkooppersoneel en goeie inruilwaarde vir vorige motor word volgens die verkoopskonsultant se persepsie van verbruikersbehoeftes, as relatief belangriker beskou as wat verbruikers dit ervaar.

\section{Semevatting}

Verkoopskonsultante is versoek on hulle in die posisie van 'n voornemende koper van 'n passasiersvoertuig te stel en dan die relatiewe belangrikheid van evalueringskriteria aan te dui. Hulle evaluasie is vergelyk met die van verbruikers.

Ten opsigte van 39 evalueringskriteria bestaan beduidende verskille op die 0,05 -vlak tussen verbruikers en verkoopskonsultante wat die evaluering van die relatiewe belangrikheid by die aankoop van 'n passasiersvoertuig betref. Verder toon 'n vergelyking van die belangrikheidsvolgorde soos gerangskik deur beide respondentgroepe min ooreenstemming. Dit wil dus voorkom of verkoopskonsultante nie ten volle op hoogte is van verbruikers se behoeftes by die aankoop van 'n passasiersvoertuig nie.

\section{Bestuurimplikasies}

Indien die beginsels en wese van die bemarkingskonsep suksesvol op die kleinhandelvlak in die motorbedryf toegepas word, behoort verkoopskonsultante op hoogte te wees van verbruikersbehoeftes. Verkoopskonsultante behoort daarom bewus te wees van die relatiewe belangrikheid van kriteria wat deur voornemende motorkopers oorweeg word voordat 'n verkoopsbesluit geneem word.

Die bevinding van die studie is dat die waarde wat verkoopskonsultante met betrekking tot die relatiewe belangrikheid van evalueringskriteria heg, soos wat hulle dit vanuit die oogpunt van die verbruiker waarneem beduidend verskil van die van verbruikers se werklike evaluering. Uit 'n verkoopsoogpunt het hierdie bevinding relatief belangrike direkte implikasies vir bestuur op handelaarsvlak en indirek vir motorvervaardigers. Indien die resultate van die studie na alle verkoopskonsultante in die universum veralgemeen kan word, suggereer dit dat daar 'n heroriëntering, deur middel van opleidingsprogramme, by verkoopskonsultante sal moet plaasvind. 


\section{Summary}

The acceptance of the marketing concept and the implementation of the principles on which it is based presuppose a thorough knowledge of market needs. If the marketing concept is applied at retail level in the South African motor industry, one should be able to assume that there is a high degree of agreement regarding the perceptions of consumers and sales personnel of what is important to a purchaser when buying a motor vehicle. The validity of this statement was tested by means of the following null-hypothesis: There is no difference in the relative importance attached to different evaluation criteria by consumers and sales personnel when purchasing a passenger vehicle.

The authors tested the formulated hypothesis, involving 902 consumers of all race groups who bought a new or used passenger vehicle for private use during the period December 1985 - May 1986 as well as 207 sales personnel.

Purchasers had to rate the relative importance of 65 evaluation criteria on a six point scale ranging from 1 (totally unimportant) to 6 (extremely important). Sales personnel were requested to rate, using any vehicle they were acquainted with as point of reference, the same criteria in the way they thought prospective vehicle buyers would rate them.

An analysis of variance revealed that there were significant differences $(p<0,01)$ between the two groups for 35 of the 65 evaluation criteria, while significant differences at the 0,05 level were found for a further four criteria. The null-hypothesis was therefore rejected with regard to 39 evaluation criteria in favour of the alternate hypothesis.

The finding that sales personnel and consumers differed in their perceptions of which criteria are important when a motor vehicle is purchased, has important implications from a sales perspective. At the retail level it may be necessary to re-orientate sales personnel by means of training programmes, while motor manufacturers should analyse their marketing strategies and evaluate them in the light of prevailing market needs.

\section{Vermysings}

Cohen, D. 1981. Consumer behavior. New York: Random House.

Du Plessis, P.J. 1986. Verbruikersgedrag by die aankoop van 'n motorvoertuig. Ongepubliseerde DBL-proefskrif. Pretoria: Universiteit van Suid-Afrika.

Engel, J.F., Blackwell, R.D. \& Kollat, D.T. 1978. Consumer behavior. 3rd Edition. Illinois: The Dryden Press.

Kotler, P. 1980. Marketing management: Analysis, planning and control. 4th Edition. New Jersey: Prentice Hall.

Kotler, P. \& Armstrong, G. 1987. Marketing: An Introduction. New Jersey: Prentice Hall.

Newsdesk. 1982. Results of a major study of the automotive market. South African Associated Newspapers (February).

Newsdesk. 1983. Automotive research in 1982. South African Associated Newspapers (April).

Rousseau, G.G. 1977. 'n Bemarkingsnavorsingsondersoek na die koopmotiewe van motoreienaars in die Suid-Afrikaanse motorhandel. Humanitas, RSA, vol.4-2.

Stewart, D. \& Hood, N. 1981. A methodology for the evaluation of segmentation policy: an empirical application of the car industry. J. Market Res. Soc. vol. 23, no. 3. 